\section{FIGHT PLAQUE WITH XYLITOL}

While fluoride has long reigned supreme in preventive dentistry, there is another name gaining support from dentists across the world: xylitol.

Xylitol is a white crystalline sugar alcohol sweetener that looks and tastes just like sugar, but with $40 \%$ fewer calories. Thanks to its unique composition xylitol is unfavourable in the metabolism of $S$. mutans - the bacteria most closely associated with dental plaque.

To take advantage of xylitol's unique properties, Spry manufactures a range of xylitol-based oral hygiene products including Spry Dental Floss and Spry Toothpaste.

Each tube of Spry Toothpaste is made with all-natural xylitol and is designed to leave teeth feeling clean, smooth and extra fresh. With a variety of flavours including Spearmint, Peppermint and now also Cinnamon, Spry Toothpaste gives users a powerful new weapon in the war on dental plaque and is available both with and without fluoride. For further information contact Anyone 4 Tea Ltd on 01428652131 or visit www. anyone4tea.com.

\section{NEEDLE-FREE SYRINGE}

INJEX UK has signed an exclusive distribution agreement for UK and Ireland with INJEX Pharma GmbH for its needle-free syringe. With the INJEX30, an extremely fine jet of medication is pushed through a micro-orifice in the syringe ampoule, using precise pressure in a fraction of a second. As well as making injections virtually pain free, the INJEX30 offers tremendous help to patients who are uncomfortable with normal injections or fear the use of needles.

A single lightweight and durable stainless-steel INJEX30 can be used for over 5,000 injections. The micro jet of medication gently penetrates the subcutaneous fatty tissue and selects the path of least resistance, avoiding damage to blood vessels, nerve fibres or osseous tissues.

The INJEX has CE, FDA and NHS approval and is already being adopted in other countries and regions.

For more information, please visit www. injexuk.com.

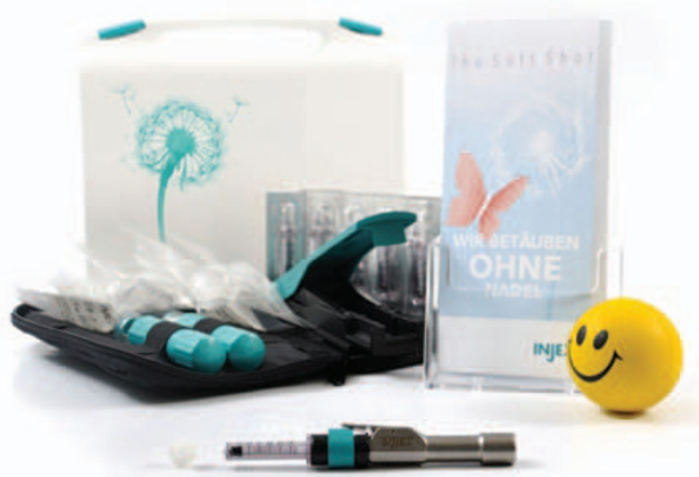

\section{STREAMLINE YOUR BUSINESS}

If running a business is interfering with the treatment of your patients, R4 Back-Office can streamline your workflow, allowing you to get back to what's really important. BackOffice can provide you with everything you need for efficient practice management and best practice compliance in one easy to use package. Developed to allow practitioners to take control of their own finances, Back-Office gives easy access to individual components of practice management such as: payroll, purchase ledger, nominal ledger, bank, stock control, petty cash, and staff records.

Back-Office even allows you to create detailed staff records for all your employees, which in turn helps you comply with outcomes 12 (Requirements relating to workers) and 14 (Supporting workers) of the CQC. With features that enable you to automatically generate reports and maximise your income potential, R4 Back-Office can help you take care of the 'business' side of your business.

For more information, contact Carestream Dental on 08001699692 or visit www.carestreamdental.co.uk. 